\title{
Reduced Atlantic Variability in the Mid-Pliocene
}

\section{G. M. Pontes ${ }^{1}$, I. Wainer ${ }^{1}$, L. Prado ${ }^{2}$, and C. Brierley ${ }^{3}$}

${ }^{1}$ Instituto Oceanográfico, Unicversidade de São Paulo, São Paulo, Brazil.

${ }^{2}$ Instituto de Geociências, Universidade de Brasília, Brasília, Brazil.

${ }^{3}$ Department of Geography, University College London, Gower St, London, UK.

Corresponding author: Gabriel Pontes (gabrielpontes@usp.br)

Address: Praça do Oceanográgfico 191/sala 166, São Paulo, SP-Brasil.

Telephone: +551130916582

\begin{abstract}
This study evaluates interannual to decadal sea surface temperature (SST) variability in the midPiacenzian warm period within the Pliocene Model Intercomparison Project (PlioMIP). Our results show significantly reduced variability at low and mid latitudes in the $\mathrm{mPWP}$ in comparison to the pre-industrial climate. At high latitudes of both hemispheres, the SST variability has increased. Latitudinal changes are likely driven by changes in the meridional SST gradient. Results with respect to the main Atlantic SST modes of variability show that the Atlantic Multidecadal Variability shifts southwards and expands eastwards due to a southward shift in the North Atlantic Drift position. The Atlantic Meridional Mode amplitude weakens in all PlioMIP models related to increased SST gradient between its two poles. The South Atlantic Subtropical Dipole significantly shifts its southwestern pole towards the South American coast. Moreover, all Atlantic modes of variability have shifted their respective frequencies towards lower values. Our analyzes on the PlioMIP simulations results provide a useful constraint in future projections associated with a warmer world when assessing Atlantic SST variability.
\end{abstract}

Keywords: Sea surface temperature variability, Atlantic Multidecadal Variablity (AMO/AMV), Atlantic meridional Mode (AMM), South Atlantic subtropical dipole (SASD), PlioMIP, midPliocene Warm Period. 


\section{Introduction}

During the Earth's history, there have been several periods in which the climate was significantly warmer than at present. Quantifying the associated responses can be useful to produce constraints on climate sensitivity. Here, we investigate climate variability in the midPiacenzian Warm Period (mPWP; $\sim 3$ to $3.3 \mathrm{Ma}$; hereafter referred as the mPWP). The mPWP was the last time that the Earth experienced similar atmospheric carbon dioxide concentrations ( 400 ppmv) to today (Seki et al. 2010). However, in the mPWP, the global ice volume was greatly reduced in both hemispheres (Denton et al. 1984; Dolan et al. 2011). The Pliocene Research, Interpretation and Synoptic Mapping (PRISM; Dowsett et al. 2012) reconstructions show a large reduction in the extent of the Greenland ice sheet and ice-free conditions in western Antarctic. In addition, the Pliocene experienced reduced meridional SST gradients (Brierley et al. 2009) that have been hypothesized to impact climate variability (Rehfeld et al. 2018).

Previous studies have looked at both proxy data and simulation results to assess the climate variability in the Pliocene. Draut et al (2003) presented geological evidence that the Pliocene epoch ( $\sim 5$ to $\sim 3 \mathrm{Ma} \mathrm{BP})$ was a period of relative climate stability, with reduced SST variability and the absence of abrupt changes, having a similar climate signature as those found for the Holocene (past $12 \mathrm{ka}$ ) or Marine Isotope Stage 11 (MIS 11; 424-374 ka BP). In addition, Dowsett et al (2005), analyzing the Pliocene Research Interpretation and Synoptic Mapping project (PRISM) estimates, reported greater SST variability at high latitudes. Most studies that examine climate variability during the Pliocene have focused on the El Niño Southern Oscillation (ENSO; Haywood et al. 2007; Scroxton et al. 2011; Watanabe et al. 2011; Brierley 2015; Tindall et al. 2016). Watanabe et al (2011) provided evidence of ENSO variability in the Pliocene by analyzing coral-based SST. Brierley (2015) found a robust reduction in ENSO amplitude and a shift towards lower frequencies from simulation results of the Pliocene Model Intercomparison Project (PlioMIP). Tindall et al. (2016) analyzed extended PlioMIP simulations of the Hadley Center general circulation model (HadCM3) to detect changes in ENSO centennial-scale variability, showing that it was less frequent and longer in duration.

The impact of mPWP boundary conditions on climate variability varies for differing latitudinal regions (Figure 1). Brierley (2015) and Tindall et al (2016) have investigated the variability of the Pacific and Indian Oceans for this period. In agreement with these studies, we also show how the spatial variability of SST is reduced for the Tropical Pacific in the PlioMIP 
models (Figure 1a). The changes for the tropical and subtropical Atlantic Ocean show a consistent pattern of reduced SST variability that has not been previously noted (Figure 1a; all models are described in Table S1). The globally averaged Tropical variability decreases in all models with a multi-model median (MMM) of 7\% (Figure 1b). The changes in variability in the Southern Hemisphere subtropics are small (Figure 1b), except if looking at the individual ocean basins. In the Northern Hemisphere mid latitudes, the variability decreases by $5 \%$. The mid latitudes have experienced the greatest warming in the mPWP (Figure 1c) and the meridional SST gradient decreases between the equator and $\sim 60^{\circ}$ in both hemispheres (Figure 1d). This, in turn, might be associated with decreased variability in low and mid latitudes (Rehfeld et al. 2018).

Polar regions in the PlioMIP models show increased variability in the Southern and Arctic Oceans by $10 \%$ and $39 \%$, respectively. It is important to note that all models show increased Arctic variability (Figure 1b). This could be associated with an increase in the SST gradient polewards of $60^{\circ}$ on both hemispheres. A big increase is seen on both PlioMIP simulations and PRISM dataset (Figure 1d). The change in subtropical-to-polar SST gradient is approximately 5 times greater than the decrease seen between low and mid-latitudes. Thus, changes in SST gradient are likely to be modulating SST variability. 
a
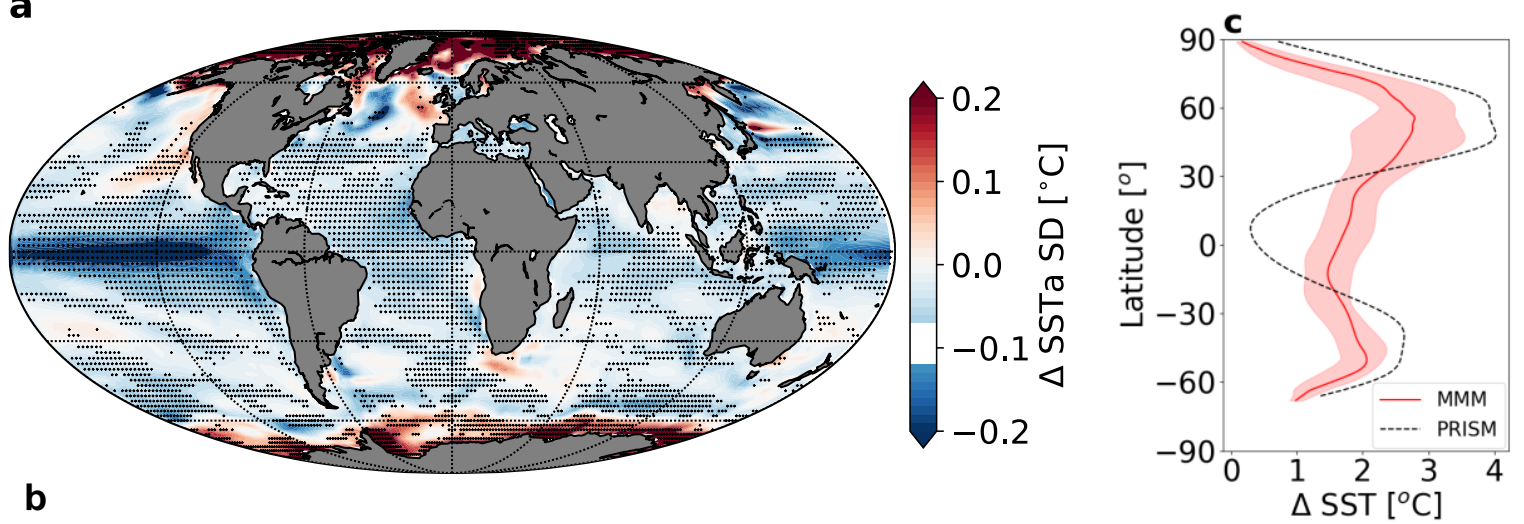

b
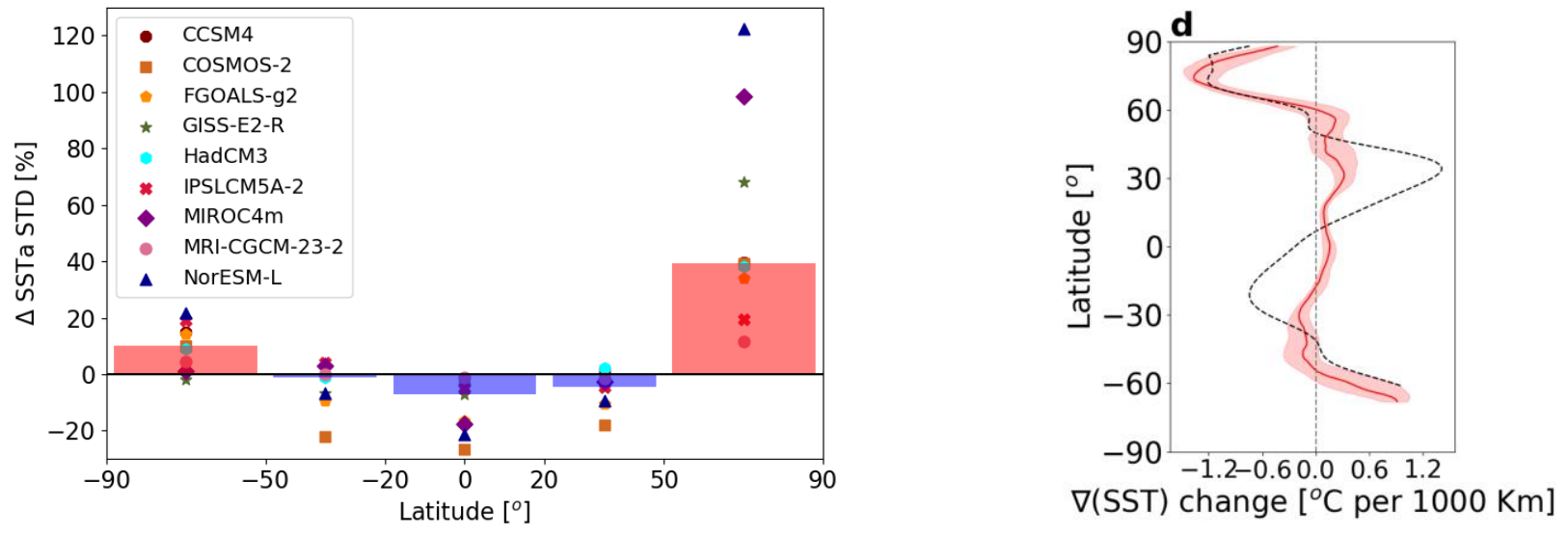

Figure 1 - Simulated variability in the mPWP. a) Multimodel mean SST anomaly (SSTa) standard deviation difference (mPWP minus piControl). Stippling indicates where at least 7 out of the 9 PlioMIP models agree on the sign of the change ( $80 \%$ model agreement). b) Multimodel median zonally averaged SSTa standard deviation difference. It represents the change in variability from piControl to the mPWP at each latitudinal zone, as indicated by the column width. The simulated mPWP variability shows an overall decrease. It is represented by low and mid latitude regions. However, high latitudes have experienced increased variability. Symbols indicate each model's value for the Antarctic region (min: -2; max: 22\%), Southern Hemisphere subtropics (min: -22 ; max: 4\%), tropical regions (-27 to $-1 \%)$, Northern Hemisphere subtropics (min: -18; max: 2\%), and Arctic region (min: 11; max: 122\%). c) PRISM SST reconstruction (black dashed line) and MMM zonally averaged SST difference (red line). d) PRISM (black dashed line) and MMM change in the zonally averaged meridional SST gradient from pole-to-pole, computed between each two consecutive grid points (red line). Both negative values in the Southern Hemisphere and positive values in the Northern Hemisphere indicate a decreased gradient. Banding on panels ' $c$ ' and ' $d$ ' indicate interquartile range.

Patterns of Atlantic SST variability are known to have impacts over continental areas, mostly through changes in precipitation. The Atlantic Multidecadal Variability, which is defined as the basin-wide leading EOF between the equator and $60^{\circ} \mathrm{N}$ in the North Atlantic (Ting et al. 2011), is associated with precipitation variability over North America and Brazil (Enfield et al. 2001; Ting et al. 2011) and with the frequency of severe tropical Atlantic hurricanes (Trenberth 
and Shea 2006). In the tropical Atlantic, the Atlantic Equatorial Mode (AEM, also known as Atlantic Niño), which is defined by the leading EOF in the tropical Atlantic $\left(20^{\circ} \mathrm{S}-20^{\circ} \mathrm{N}\right.$ and $60^{\circ} \mathrm{W}-20^{\circ} \mathrm{E}$; e.g. Deser et al. 2010), intensifies atmospheric convection at the equator, holding the Atlantic rain belt at its southern position (Giannini et al. 2003). The Atlantic Meridional Mode (AMM), which is represented by the second EOF in the tropical Atlantic (Deser et al. 2010), is strongly associated with the meridional displacements of the Intertropical Convergence Zone (ITCZ; Wainer and Soares 1997; Lübbecke et al. 2018). In the Southern Hemisphere, the South Atlantic Subtropical Dipole (SASD), represented by the leading EOF between the equator and $50^{\circ} \mathrm{S}$ and $60^{\circ} \mathrm{W}-20^{\circ} \mathrm{E}$ (Morioka et al. 2011), has been associated with changes in precipitation of opposite polarity over northeastern and southeastern Brazil (Morioka et al. 2011; Wainer et al. 2014). These Atlantic modes of variability impact the location and distribution of precipitation. Therefore, an investigation of the changes in these modes in the mPWP may provide a useful constraint for possible future projections associated with a warmer world.

In this study, we aim to verify changes in the spatial structure, frequency, and moments of the Atlantic SST variability modes using the output of all nine coupled model participants in the PlioMIP (see section 2.1; Table S1). The modes to be analyzed are: AMV in the North Atlantic, AEM and AMM in the Tropical Atlantic, and the SASD in the South Atlantic.

\section{Methods}

\subsection{Models and Data}

The PlioMIP initiative was developed to investigate the climate of the interglacial mPWP. Here, we use outputs of PlioMIP phase 1 experiment 2 only. For this experiment, coupled climate models were tasked to simulate average climate conditions for the period between $\sim 3.3$ and $\sim 3$ million years ago (Haywood et al. 2011; Table 1). In these simulations, the greenhouse gas (GHG) forcing is set to $405 \mathrm{ppm} \mathrm{CO}_{2}$, the orbital configuration is not changed from modern configuration, and the prescribed boundary conditions, which includes orography, ice sheets, vegetation, and land/sea mask, are given by the PRISM reconstructions (Dowsett et al. 2010). Details of the implementation of each model are found in the references listed in Table $\mathrm{S} 1$. The control simulation is run with boundary conditions of the pre-industrial period (piControl). In this simulation, $\mathrm{CO}_{2}$ concentrations set to $280 \mathrm{ppm}$. It allows us to make direct comparison between the simulated pre-industrial climate and the simulated Pliocene climate. 
There are two well-accepted techniques to detect SST modes of variability: index-driven metrics and through the calculation of empirical orthogonal functions (EOFs). Both techniques are computed with anomalies that are obtained by removing the averaged annual cycle from the original time series. The most common detection is made through index-driven metrics and is usually the mean over a given area (e.g., Zebiak 1993) or the difference between two areas (e.g., Wainer et al. 2014). This metric assumes that the pole of variability does not change its position. Therefore, to be able to evaluate spatial changes in the SST modes, we opt for defining them through the computation of EOFs. EOF analysis allows us to separately study changes in the spatial structure for both frequency and amplitude, which is achieved by normalizing the EOF spatial pattern by its spatial standard deviation (e.g., Power et al. 2013; Brierley 2015).

Frequency and amplitude analyses are computed from the EOF-associated time series. The spectral analysis methodology described by Mudelsee (2014) using Welch's overlapped segment averaging procedure is adopted. Since the weight given by the EOF analysis for its respective time series may differ from model to model, all EOF time series were normalized by their own standard deviation before applying the spectral analysis. In this manner, we isolate the influence of amplitude, as well. The dominant frequency is defined as the frequency with the greatest power density in the spectrum.

Following the methodology used by Brierley (2015), we also analyze the moments of the distribution of the modes of variability for each of the PlioMIP model simulations. These moments include standard deviation, skew, and kurtosis. The standard deviation is a powerful metric for the amplitude of the distribution of SST anomalies (e.g., Taschetto et al. 2014; Brierley 2015). Skewness measures which tail of the distribution is stronger. In our case, a positive skew means that the positive phase of the mode is stronger than the opposite one and vice versa. Kurtosis measures whether most events occur near the mean or not. A higher kurtosis coefficient represents a more peaked distribution, and fewer extremes occur. We present skew and kurtosis results whenever there are coherent results among PlioMIP models.

In this study, we opt for using multimodel medians because of the difference in distribution among the different model's simulation results as in Pontes et al (2016). Multimodel means are used in two cases: 1) when plotting multimodel maps because the use of medians can distort the patterns; 2) when just a few models have the available variables for the analysis; in this case the median is not representative of the distribution. Here, we use the output of nine 
climate models (table S1). Thus, the median is defined as the fifth value (in increasing order) of the ensemble. The interval between the third and seventh positions represents the interquartile range. Therefore, unless specified, all values presented are multimodel medians (MMM) followed by the range of all models, which includes extreme models.

\section{Results and Discussion}

\subsection{Atlantic Multidecadal Variability (AMV)}

All PlioMIP models have represented the AMV pattern in theirs respective leading EOF over the North Atlantic in both pre-industrial and Pliocene climates (Figure 2a; See sect. 2). These patterns are consistent with the horseshoe pattern observed in the HadISST, however, some models show a bias in the position of the AMV pole at extra-tropical latitudes (Figure S1). The mPWP multimodel mean results show significant spatial changes, which can be observed in the difference map (mPWP minus piControl; Figure 2b). The difference shows that the positive AMV pole expands equatorwards and eastwards for at least 6 out of 9 models.
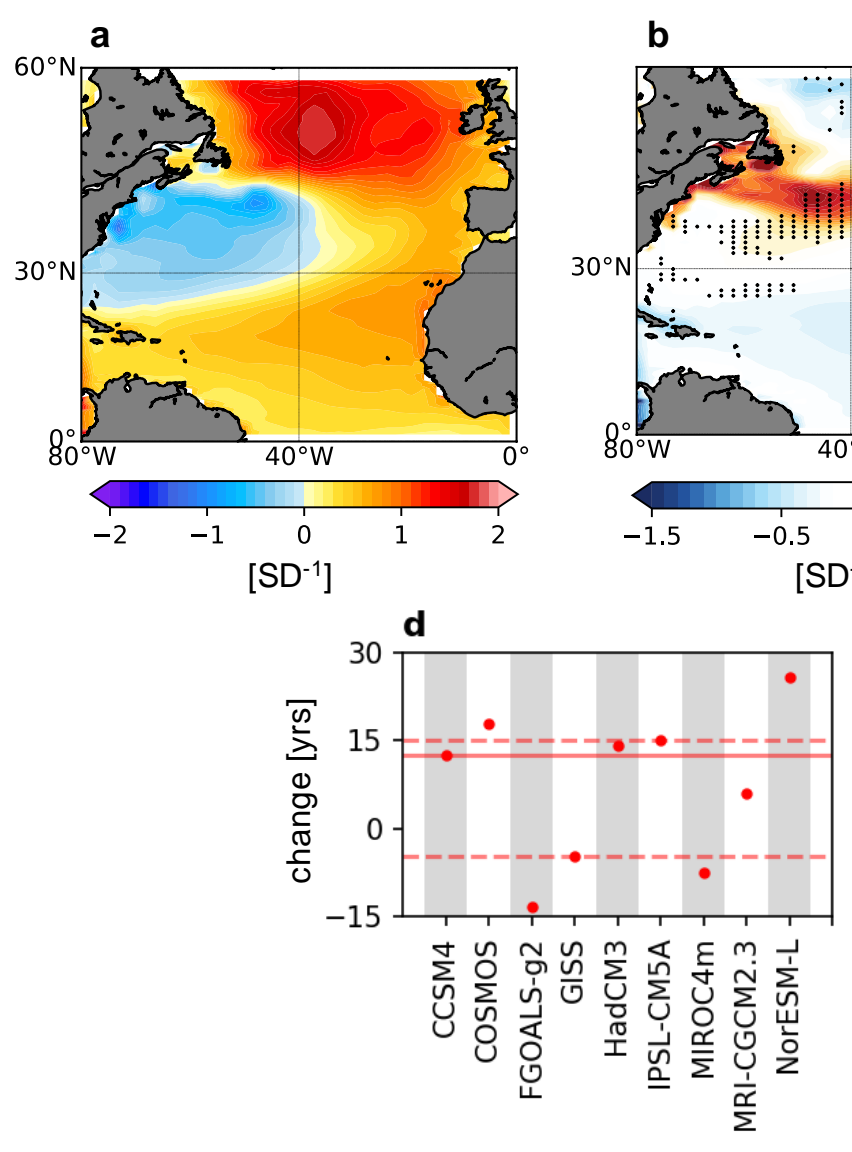
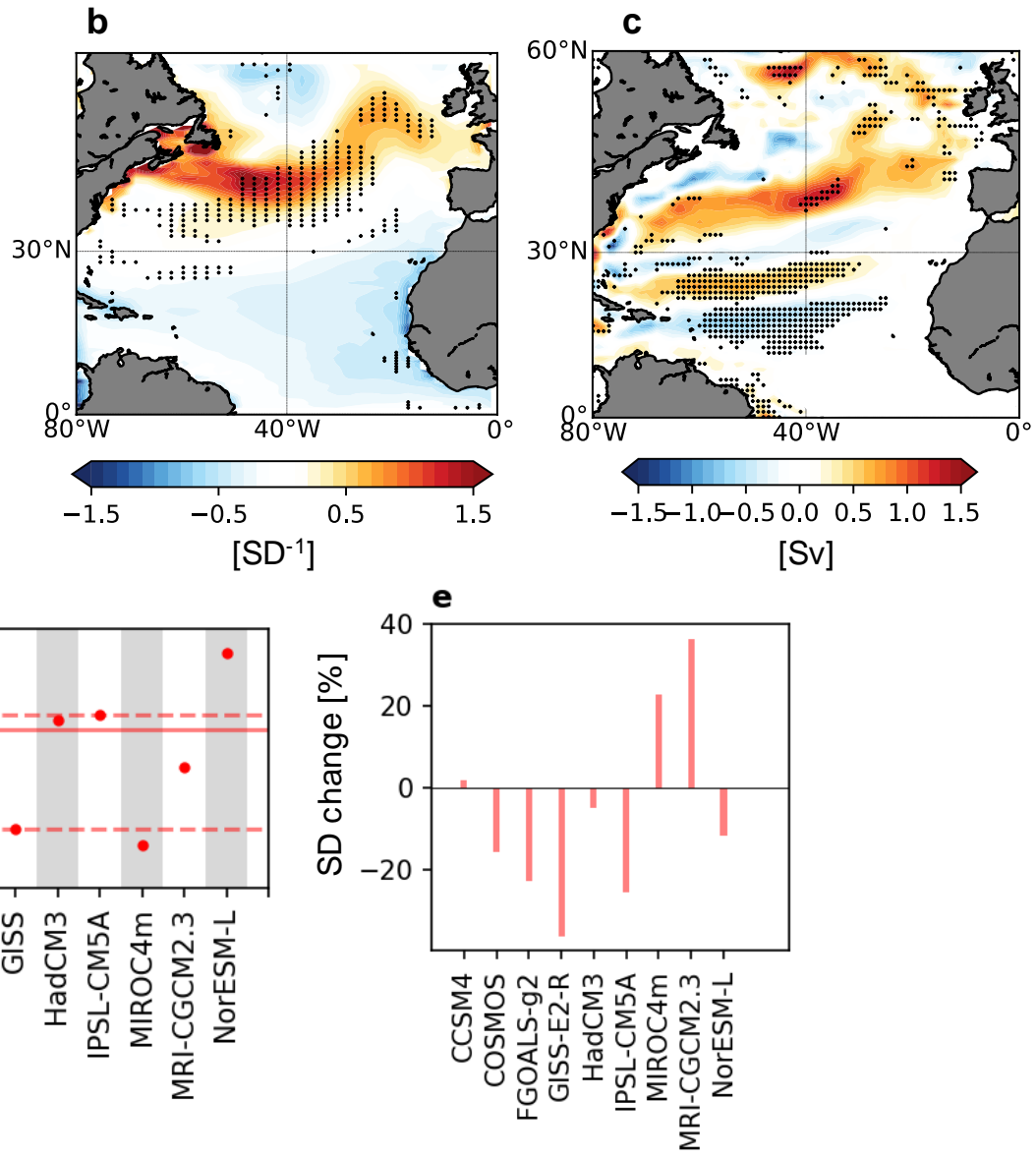
Figure 2 - Multimodel analysis of the Atlantic Multidecadal Variability (AMV). a) piControl multimodel mean structure. It captures the observed HadISST structure (Figure S1). b) Normalized multimodel mean difference (mPWP minus piControl; units: $\mathrm{sd}^{-1}$ ). Stippling indicates regions where there is a $\sim 80 \%$ (at least 7 of the 9 PlioMIP models) agreement on the sign of the difference. The AMV pole has significantly expanded southwards and shifted eastwards. c) Multimodel mean change of the intensity of the North Atlantic transport integrated up to $1000 \mathrm{~m}$. The multimodel mean indicates an equatorward shift of the NAD and intensification of the sub-polar gyre. The change for each model is shown in Figure S2. Stippling indicates a model agreement of at least 6 out of 7 models. d) Spectral analysis results. This panel shows the difference in the AMV power spectrum between the most energetic period for the mPWP and piControl simulation results. The power spectra for the individual models are shown in Figure S3. All but three models (FGOALS-g2, GISS, and MIROC4m) shift towards higher periods in the mPWP. e) Difference in the time series standard deviation (mPWP minus piControl).

The AMV has been recently shown to be dominated by ocean-atmosphere interactions (Clement et al. 2015), in contrast with the previous idea where the AMV was considered to be a surface fingerprint of the natural oscillation of the Atlantic meridional overturning circulation (AMOC; Delworth and Mann 2000). However, the second hypothesis can still play a role on longer timescales than the AMV, where an intensification of the AMOC may amplify the North Atlantic warming (Karas et al., 2017). The most recent hypothesis (Clement et al., 2015) suggests that the positive (negative) AMV pattern is a result of weaker (stronger) atmospheric subtropical high and poleward (equatorward) shift of the westerly jet, which results in weaker (stronger) westerly winds in mid-latitudes that decelerates (intensifies) the ocean circulation and, thus, converging heat. Thus, in both hypotheses the AMV pole depends on the position of the North Atlantic Ocean currents. This way, the equatorward shift in the AMV pole can be linked to the equatorward shift in the North Atlantic drift (NAD). The NAD delimits the northern boundary of the North Atlantic Subtropical Gyre, being responsible for heat advection from the Gulf Stream to higher latitudes across the North Atlantic (Sarmiento and Bryan 1982). The changes in the intensity of the North Atlantic Ocean transport integrated up to $1000 \mathrm{~m}$ (for all models except FGOALS and IPSL, which did not contribute velocity data to the PlioMIP database) reveal a southward shift of the North Atlantic drift and intensification of the sub-polar gyre (Figure 2c). There are minor regions of good model agreement as the position of the North Atlantic currents vary from model to model (Figure S2). Nonetheless, the changes in the North Atlantic transport are consistent with changes in the AMV structure in each model (Figures S1, S2). A given model may move its AMV pole northwards even with a southward shift of the 
NAD if the model also strengthens its sub-polar gyre (ex. GISS and NorESM). The eastward expansion of the AMV is related to an intensification of the NAD eastwards of 40W (Ex. CCSM4, GISS, HadCM and MRI). Thus, the position of the AMV pole depends on the position of the North Atlantic Ocean currents.

These findings suggest that the North Atlantic drift in the mPWP is likely to have been south of its present position, as was the AMV pole. In fact, proxy data studies have estimated a southward shift and slowdown of the NAD during the Pliocene (De Schepper et al. 2009; Friedrich et al. 2013). Furthermore, Chandan \& Peltier (2017) found, using the UofT-NCAR model results, a southward shift of the Northern Hemisphere westerlies. However, to be assured about the North Atlantic scenario in the mid-Pliocene a larger ensemble is needed in order to analyze these changes through more robust statistics.

The AMV has an observed period of 63.3 years (Figure S3j). The PlioMIP models examined here do not capture the AMV observed frequency (Figure S3). Nonetheless, 6 of the 9 models shift their respective highest power frequency towards lower frequencies. It is only statistical significant at the $90 \%$ level (further discussed in sect. 3.5), but initially suggests a longer AMV period in the mid-Pliocene. The MMM change in this period is 12.5 years (from 13.4 to 25.9 years; Figure $2 \mathrm{~d}$ ).

The sign of the change in AMV amplitude varies across the PlioMIP models (Figure 2). The MIROC4m and MRI-CGCM2.3 models simulate the mPWP AMV with increased variances of $23 \%$ and $36 \%$, respectively. The CCSM4 and HadCM3 models show no change. On the other hand, the simulation results from the remainder of the PlioMIP models show the AMV weakening. Thus, there is no consistency in the changes in AMV amplitude (Figure 2e). Delworth \& Greatbatch (2000) reported that the presence of extratropical air-sea modes depends on the intensity at which the atmosphere responds to mid-latitude anomalies on both SST and sea ice in General Circulation Models. In this manner, the differing changes in AMV amplitude shown here are most likely associated with differing atmospheric responses to mPWP warmth and reduced sea ice in each model.

The most significant change in the AMV is related to its structure. The southward and eastward expansion of the AMV pole changes heat advection to North America and Europe. In modern climate, the precipitation changes associated with the AMV variability has a major impact over North America. However, the expansion of the AMV pole and the southward shift in 
the NAD can possibly strengthen the impact of the AMV over Europe precipitation and amplify its impact over North America. In addition, the expansion of the warming region at extratropical latitudes can potentially shift the Inter-Tropical Convergence Zone northwards, increasing precipitation over the Sahel region and amplifying droughts over northeastern Brazil.

\subsection{Tropical Atlantic Modes}

The two tropical Atlantic modes of SST variability arise as the first two EOFs over the area between $20^{\circ} \mathrm{S}-20^{\circ} \mathrm{N}$ and $60^{\circ} \mathrm{W}-20^{\circ} \mathrm{E}$ as in Deser et al (2010). The first mode is known as the AEM, also known as Atlantic Niño mode (NINO ATL3; Zebiak 1993), which is characterized by the Atlantic equatorial cold tongue. The individual PlioMIP model's representation of the Atlantic Niño differs considerably (Figure S4). The majority of the models generally have a poor representation of this variability mode making it difficult to evaluate and interpret changes either in spatial structure or on the temporal variability.

The AMM is the EOF2 spatial pattern of SST anomalies in the tropical Atlantic (Deser et al. 2010; Figure 3a). It represents an interhemispheric SST-gradient that shows opposite SST anomalies on either side of the equator. The AMM EOF2 pattern for most of the PlioMIP models is consistent with the observed HadISST pattern (Figure S5), as well as its multimodel mean (Figure 3a). The AMM in the NorESM-L model is difficult to define as both EOFs present a dipole pattern (Figures S4 and S5). We have chosen EOF2 in this model because it has a stronger dipole structure, which is the main pattern of AMM, even though it is confined to the African coast (Figure S5). The mPWP simulation results for the AMM show regions of significant changes. The difference (mPWP minus piControl) suggests a westward expansion of the northern pole (Figure $3 b$ ). The southern pole does not show large regions with significant changes. 

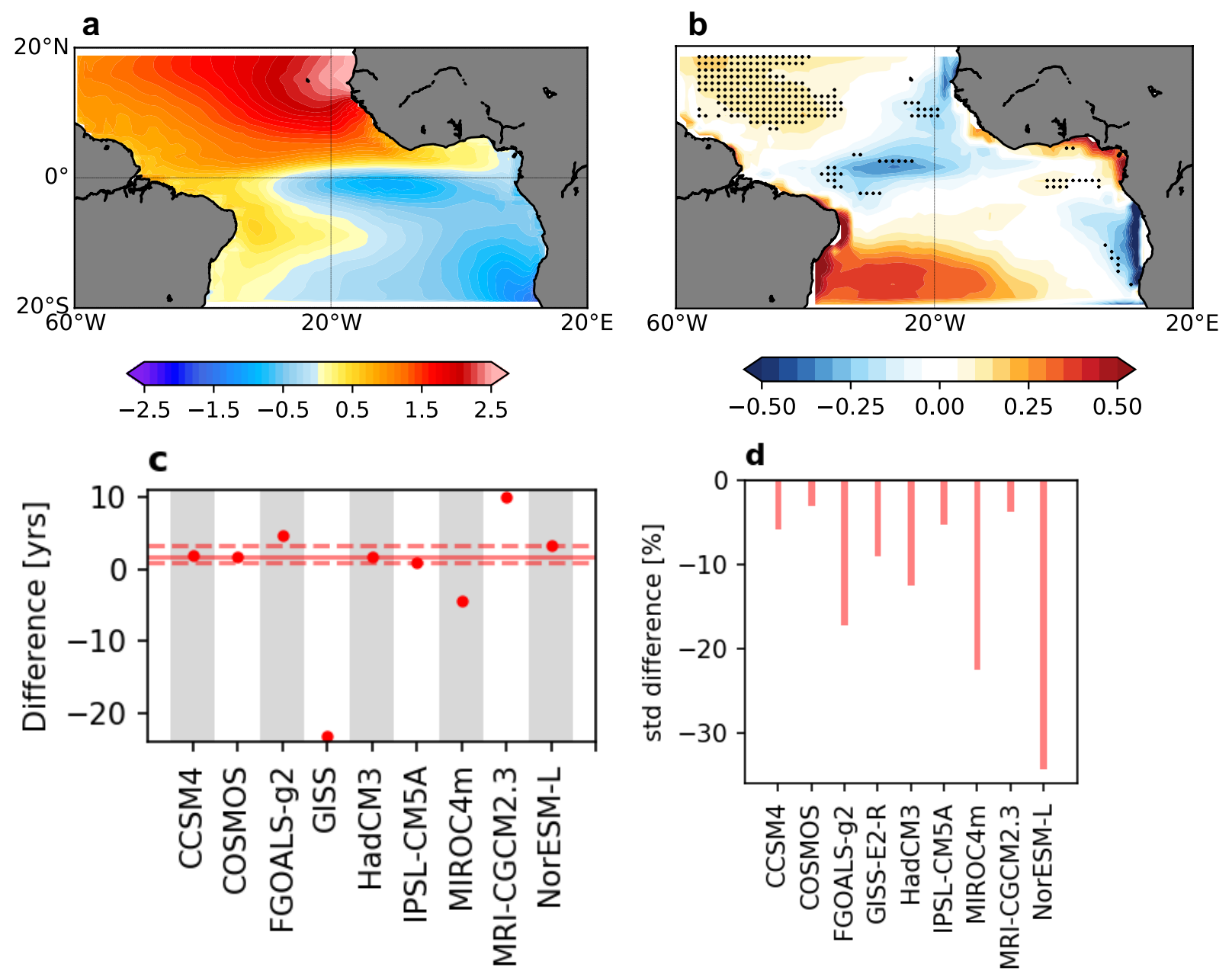

Figure 3 - Multimodel analysis of the Atlantic Meridional Mode (AMM). a) piControl multimodel mean. The spatial structure is similar to that of the observed HadISST (Figure S5). b) Normalized multimodel mean difference (mPWP minus piControl; units: sd $^{-1}$ ). Stippling indicates regions where there is a $\sim 80 \%$ (at least 7 of the 9 PlioMIP models) agreement on the sign of the difference. The AMM pole has significantly expanded westwards. c) Spectral analysis results. This panel shows the difference in the AMM spectrum between the main period of the mPWP and piControl simulations. The power spectra of the individual models are shown in Figure S6. All models, except MIROC4m, shift towards higher periods in the mPWP. d) Difference in time series standard deviation (mPWP minus piControl). All models have simulated reduced AMM amplitude in the mPWP simulation.

The dominant period for the $20^{\text {th }}$ century HadISST observed dataset is 11.6 years (blue line on the HadISST panel on Figure S6j). The dominant period for the piControl MMM is 7.7 (from 1.3 to 44.3). The extreme models are COSMOS, which simulates the AMM at a recurrence 7 times greater $\left(\sim 7\right.$ cycles.decade $\left.{ }^{-1}\right)$, and GISS, which simulates it at multidecadal timescales ( $\sim 23$ cycles.decade $^{-1}$; Figure S6). In the mPWP simulation, the AMM power spectra show a 
shift in frequency towards lower values for 7 out of the 9 models. The MMM change in period is 1.7 (from -23.1 to 10 years; Figure $3 \mathrm{c}$ ).

The analysis of the moments of the AMM distribution shows consistent changes. The AMM amplitude weakens for all PlioMIP models (Figure 3d) with a MMM of $-9 \%$ ( -35 to $-3 \%$ ). The observed distribution of AMM is negatively skewed (Figure S7a), meaning that the stronger phase of this mode occurs with negative SST anomalies in the Northern Hemisphere and opposite values in the Southern Hemisphere (opposite of what is shown in Figure 3a). This pattern was captured by two-thirds of the models in the piControl simulation (Figure S7a) and in 5 of them the AMM skewness changes towards positive values in the mPWP.

The decreased AMM variability is consistent with changes in the AMM meridional SST gradient. The AMM SST gradient is defined as the mean SST difference between the northern pole $\left(5^{\circ}-15^{\circ} \mathrm{N}\right.$ and $\left.20^{\circ}-70^{\circ} \mathrm{W}\right)$ and the southern pole $\left(15^{\circ}-5^{\circ} \mathrm{S}\right.$ and $\left.20^{\circ} \mathrm{W}-10^{\circ} \mathrm{E}\right)$ as in Brierley \& Wainer (2018). We find a good relationship ( $\mathrm{r}=0.6$, significant at the $80 \%$ level) among models where an increase in the AMM SST gradient change is associated with a decrease in AMM amplitude (Figure 4a). This result is in agreement with (Brierley and Wainer 2018), who found the same relationship for the mid-Holocene and opposite for the Last Glacial Maximum (LGM).

The increased AMM gradient is associated with changes in the surface winds, especially over the North Tropical Atlantic (NTA; Figure 4b). Due to that, two important positive feedbacks likely operate. The first one is the wind-evaporation-SST (WES) feedback, where the weakening of the northeast trade winds reduces the surface latent heat flux, increasing SST. This further increase in the NTA SST reinforces the AMM gradient. The second process is the feedback associated with ocean upwelling. The weakening of the northeast trade winds dampens the upwelling of cold waters along the northwest African coast. It results in a constant anomalous warm NTA that decreases the AMM variability. In addition, the winds over the Benguela upwelling in the South Tropical Atlantic slightly intensify contributing to increased AMM gradient in the mPWP. These results indicate that the warming in the NTA region (as in the midHolocene and mPWP) is associated with the decrease of the AMM amplitude. 

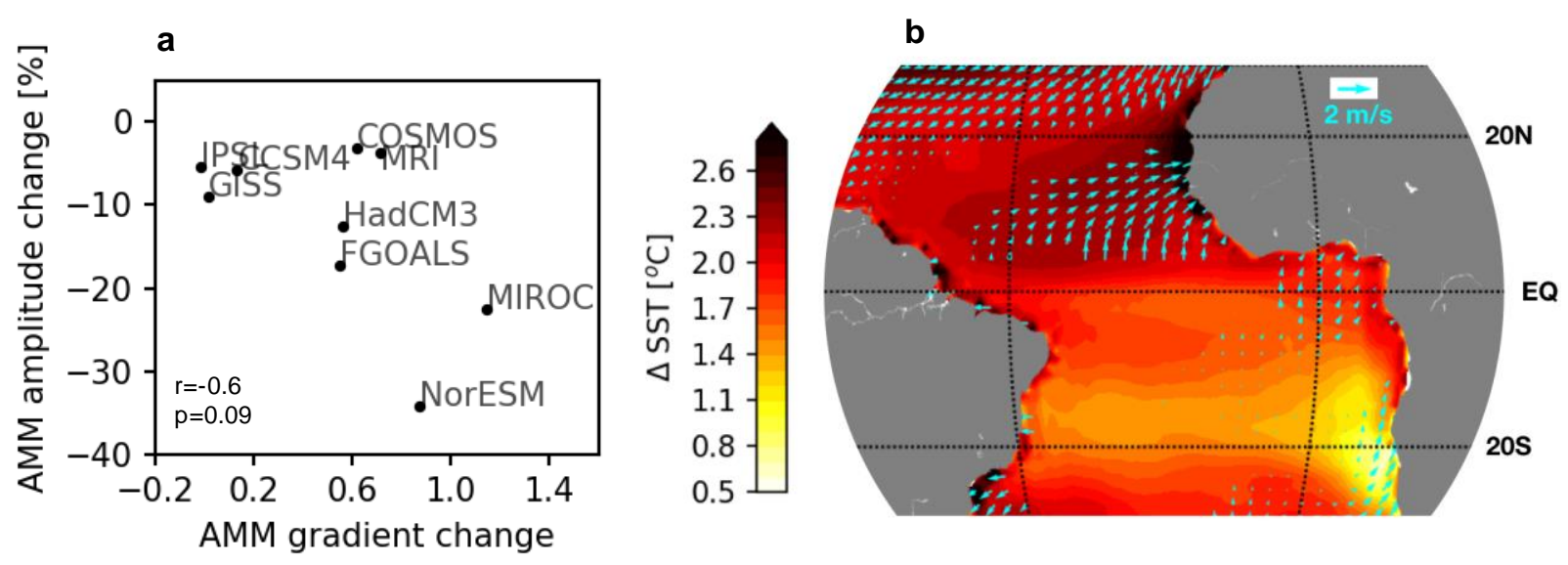

Figure 4 - a) Relationship between AMM amplitude change and AMM SST gradient change (mPWP minus piControl). ' $r$ ' indicates the Pearson's correlation coefficient and ' $p$ ' the twotailed p-value. b) Colors: multi-model mean SST change. Vectors: multi-model mean wind change, showing regions where there is at least a $70 \%$ model agreement.

All changes evaluated in the AMM analysis are consistent and extremely effective in modifying rainfall over the Tropical Atlantic. The weakening of the northeast trade winds, reduced northwest Africa upwelling, expansion of the northern AMM pole, and increased AMM gradient are all consistent with a northward shift of the Inter-Tropical Convergence Zone (ITCZ; Figure 4). This way, the mPWP ITCZ-related rainfall is displaced into the Northern Hemisphere as it follows the warm SST anomalies, increasing rainfall over Cariaco and Sahel and reducing the precipitation over northeastern Brazil and southwestern Africa. In addition the positive skewness change reduces the number of events in which the ITCZ is displaced southwards. These changes also contribute to increased North Atlantic hurricane activity in this period (Fedorov et al., 2010).

\subsection{South Atlantic Subtropical Dipole}

The SASD has a dipole structure oriented in the northeast-southwest direction. This mode corresponds to the leading EOF in the South Atlantic over the area between $50^{\circ} \mathrm{S}-0$ and $60^{\circ} \mathrm{W}$ $20^{\circ} \mathrm{E}$ (Figure 5a). The SASD modifies rainfall in most of Brazil. For example, the cold pole weakens convection, decreasing moisture advection to the continent through wind changes (Wainer et al. 2014). The individual models were able to simulate a realistic SASD spatial pattern when compared to observations from the later part of the $20^{\text {th }}$ century (Figure S8). 
Significant changes in the pattern of the SASD are clearly seen from the difference plot between the mPWP and piControl (Figure 5b). The southwestern pole moves towards the South American coast. This shift can potentially amplify the impact on rainfall/droughts over southeastern South America. A negative (positive) SASD pole closer to the subtropical South American coast intensifies a cyclonic (anticyclonic) wind gyre over itself transporting humidity from the Atlantic ocean to South America (away from the coast), increasing (decreasing) rainfall over subtropical South America. In addition, the northeastern pole significantly weakens, which in its turn, can reduce its impact in rainfall over northeastern Brazil and southwestern Africa.

a

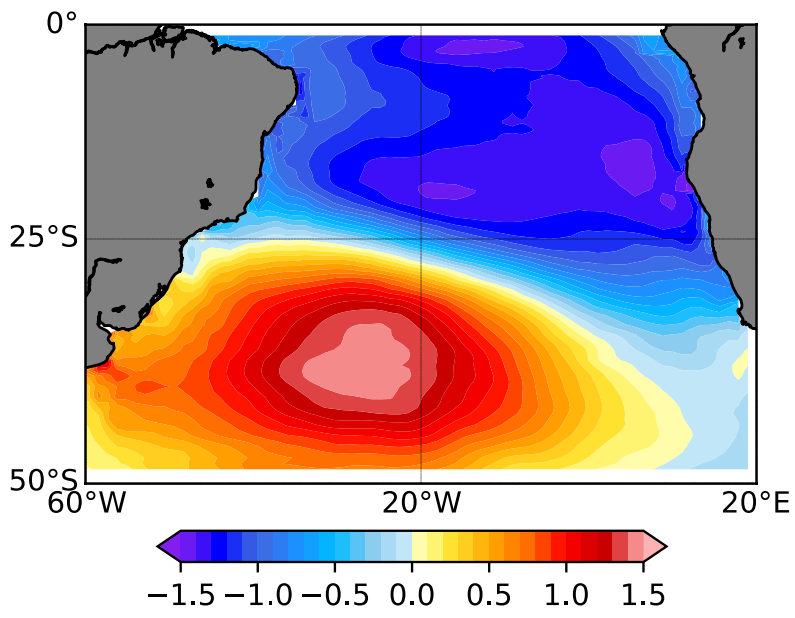

C

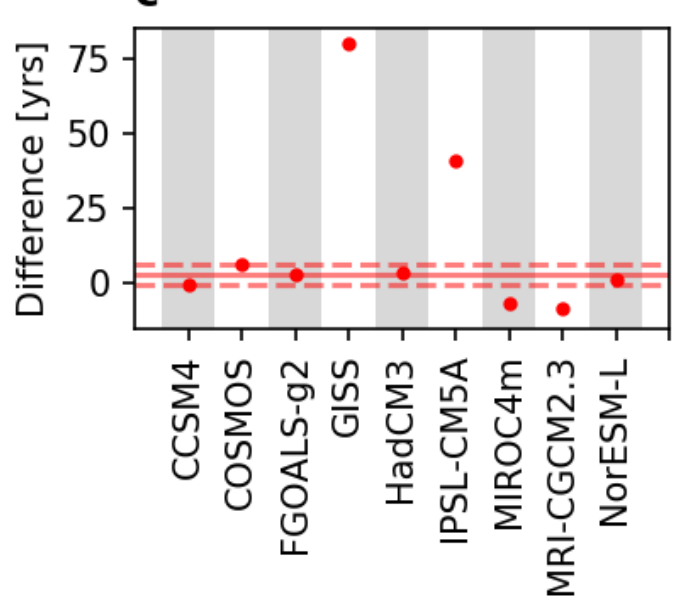

b

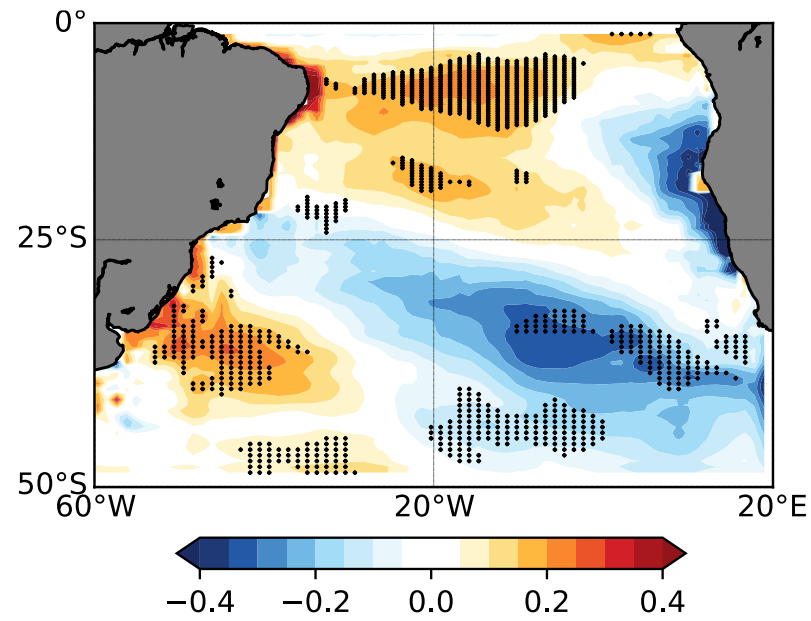

d

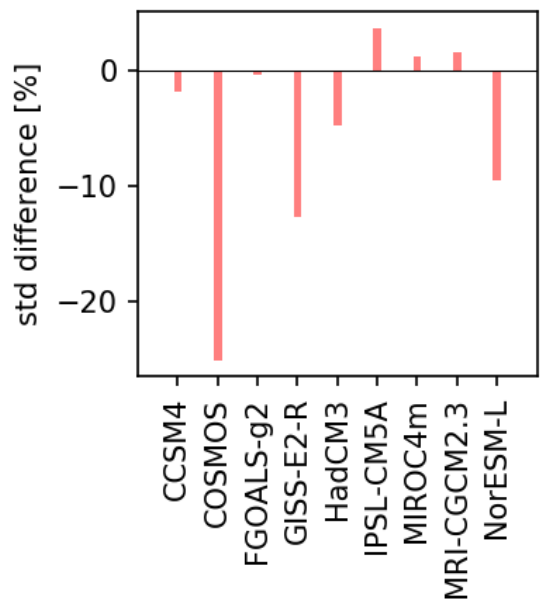

Figure 5 - Multimodel analysis of the South Atlantic subtropical dipole mode (SASD). a) piControl multimodel mean. It captures the observed HadISST structure reasonably well (Figure S8). b) Normalized multimodel mean difference (mPWP minus piControl; units: $\mathrm{sd}^{-1}$ ). Stippling indicates regions where there is a $\sim 80 \%$ agreement on the sign of the difference (at least 7 of the 9 PlioMIP models). Changes show overall weakening of the northeastern pole and westward shift of the southern pole. c) Spectral analysis results. This panel shows the difference in the 
SASD power spectra between the main period in the mPWP and piControl simulations. The spectra for the individual models are shown in Figure S9. All but 3 models (CCSM4, MRICGCM2.3 and MIROC4m) shift towards higher periods in the mPWP. d) Difference in the time series' standard deviation.

The power spectrum for the SASD mode in the HadISST observed dataset has two significant peaks (blue line on HadISST panel in Figure S9j). The major peak is at 12 years, while the second one is at $\sim 5$ years. The SASD highest power for the MMM piControl is at 4.9 years (from 3.4 to 31.2 years). The extreme model is GISS-E2-R that simulates SASD at decadal timescales. The highest power for the mPWP spectra increases in 6 out of 9 models (Figure 5c). The MMM change in the highest power is 2.82 (from -8.2 to 79.8; Figure 5c). It should be noted that the SASD power spectrum is poorly represented among the individual PlioMIP models (Figure S9a-i). This change indicates a shift towards higher periods, being significant at the $90 \%$ (see sect. 3.5).

The majority of the models (6 out of 9) show no change in amplitude of the SASD from the mPWP with respect to piControl (change <5\%; Figure 5d). The others (3 of 9) show a reduction in amplitude. The distribution of the SASD is positively skewed throughout the $20^{\text {th }}$ century (Figure S10a), which means that the stronger phase has positive SST anomalies in the southwestern pole (as represented on Figure 5a). All models, except for HadCM3, have simulated the SASD positive skew in the piControl simulation (Figure S10a). From these 8 models, 7 have changed the SASD skewness negatively in the mPWP simulation. Thus, the SASD negative phase has prevailed in the mPWP indicating that the stronger SASD events have advected heat from the ocean into the subtropical South American and can be associated with floods over southeastern South America in the mPWP.

\subsection{Frequency}

The climate models analyzed here have difficulties in reproducing the dominant frequency of the Atlantic modes of variability when compared to observations. The major difficulty is related to reproducing the multidecadal timescale of the AMV. On the other hand, the models tend to better represent higher frequencies (interannual to decadal), as for AMM and SASD). This fact has also been reported in CMIP5 studies (Cheung 2017). We hypothesize that it may be related to forcings uncertainty represented in climate models, some inconsistencies between modeled and real-world spatial patterns of internal variability, and well-known model biases in upwelling 
regions (Eyring et al., 2019). However, given that the simulations (piControl and mPWP) are governed by the same model physics we assume that the change (anomaly) in frequency still is valuable information in understanding different climate scenarios.

The power spectra of the PlioMIP models results show a shift towards lower frequencies for all modes of variability analyzed here. Our results suggest that higher temperature conditions may dampen higher-frequency climate variability. Draut et al (2003) have analyzed forced variability through core data indicating the prevalence of low frequency climate variability during the Pliocene epoch. Internal variability in the mPWP has been analyzed in climate models only (e.g. Brierley 2015; Tindall et al. 2016). These studies reported that the mPWP ENSO was less frequent than in pre-industrial climate. Internal variability in the Last Interglacial (119-116 ka BP) in the North Atlantic and was found to have a higher frequency than in the Holocene (Tzedakis et al. 2018). However, the mechanisms behind changes in frequency with respect to the internal variability of past climates remain an open question.

\subsection{Statistical significance}

In this study we use model agreement to analyze the statistical significance of the changes that were described. The model agreement method is based on a binomial distribution with $p=q=$ 0.5. Thus, we assume that the probability of the sign of the change in each model being positive $(p)$ is 0.5 , which is equal to that the sign being negative $(q)$. The cumulative distribution function shows that for 9 models $(N=9)$ the probability of having an approximately $80 \%$ model agreement (7 out of 9 models) is very unlikely (significance level $=98 \%$ ) and that an agreement of 6 out of 9 models is significant at the $90 \%$ level (Figure S11). Hence, we use at least the level of $90 \%$ to state that a given change is statistically significant. Depending on the analysis the number of models may change due to the availability of the necessary variables in the PlioMIP portal. For $N=7$ the $90 \%$ level corresponds to an agreement of 5 models and for $N=6$ to 4 models (Figure S11). This method has been shown to be as robust as others commonly used metrics to evaluate changes, such as comparing the multimodel mean to the intermodel standard deviation and analyzing the magnitude of the multimodel mean of normalized change (Power et al., 2012). One would be much more confident that the changes described in this study are real features of the mPWP climate if underlying mechanisms are found to explain them as we proposed for changes in AMV structure, AMM changes, and changes in frequency. 


\section{Summary and Conclusions}

SST variability has been investigated with the simulation results of the 9 models participating in the PlioMIP. Our findings indicate a decrease in tropical SST variability of around -7\% (-27 to $1 \%)$, and increased variability of the polar regions of both hemispheres $(+10 \%$ [-2 to $22 \%]$ in Southern Ocean and $+39 \%$ [11 to $122 \%$ ] in the Arctic). Our analyzes suggest that SST variability is associated with meridional SST gradients, as hypothesized by Rehfeld et al (2018). We show that the reduced SST-gradient between tropical-subtropical regions is accompanied by decreased variability. In polar regions, however, there is an increase in variability accompanied by an increase in the subtropical-to-polar SST-gradient. In addition, ice cover could play a secondary role in regulating climate variability as they isolate property exchanges (e.g., heat) between the atmosphere and the subjacent surface (land or sea).

Climate variability in Atlantic Ocean SST modes in the PlioMIP ensemble was investigated. Each of the characteristics of the modes of variability has a different impact in the associated precipitation. The structural changes in the Atlantic SST modes of variability can modify the main pathway of heat advection to continental areas and impact land precipitation differently than they do in the modern climate. On the other hand, changes in frequency and amplitude do not exactly modify the affected areas, but they do affect its duration and intensity, respectively.

Our finding indicate possible changes in the rainfall associated with the Atlantic modes of variability (AMV, AMM and SASD) in the mPWP as their structure changed appreciably. The AMV pole shifts equatorward and expands towards the European coast accompanying changes in the position and intensity of the North Atlantic Ocean currents. It may expand the area affected by its precipitation changes at lower latitudes and increase it impacts over Europe. The AMM's northern pole expands eastward keeping the tropical rain belt in the Northern Hemisphere. The southern pole of the SASD in the mPWP simulation results shifts towards the South American coast. This change may intensify heat advection away (to) southeastern South America in the SASD positive (negative) phase. The Atlantic Equatorial Mode was poorly simulated and could not be evaluated in the mPWP.

Results for frequency and amplitude of the simulated Atlantic modes of variability for the mPWP indicate reduced variability. Although some models show changes in amplitude of the extratropical variability modes, these changes are not consistent across models. All models show 
reduced AMM amplitude in the MPWP that are related to increased AMM SST gradient due to weaker northeast trade winds and thus, inducing positive WES feedback and reduced upwelling along the northwest coast of Africa. In addition, the majority of the models show changes in the power-spectrum associated with the time series of each of the modes of variability towards lower frequencies, where we conclude that the Atlantic variability modes were less frequent in the mPWP. In this way, the Atlantic modes of variability had a weaker influence on mPWP climate than they do at present.

A key uncertainty of this study lies on the ability of the climate models to reproduce the Atlantic modes of variability. Both spatial pattern and frequency could be improved. The AMV spatial pattern can be improved through a better representation of the North Atlantic Ocean circulation, which may also depends on model resolution. A good representation of the AEM and the AMM depends on the ability of the model to simulate the tropical Atlantic upwelling regions, where the models show well-known biases (Eyring et al., 2019). Finally, frequency may be better simulated once spatial pattern and forcings uncertainty are improved.

These results may have important consequences for changes in teleconnections associated with a warmer world. The majority of the SST modes of variability have weakened and/or experienced reduced frequency in the PlioMIP ensemble (i.e ENSO (in Breierley [2015], AMV, AMM, and SASD) that can likely reduce their broader impact. In particular, two important tropical modes of variability, ENSO and AMM, have significantly weakened. ENSO is known to affect the North Tropical Atlantic (NTA) through changes in the Walker circulation, while NTA feedbacks onto ENSO through Rossby waves generated due to a Gill-type response (Cai et al. 2019). These PlioMIP results indicate weakened ENSO-AMM teleconnections in a warmer scenario. In order to be more confident about changes in teleconnections further analysis of temperature, precipitation, and wind variability are needed. This possible feature of the mPWP climate needs to be further explored as it is of global interest precisely quantifying the impact of the modes of variability in warmer climates.

\section{Acknowledgments and Data}

This work would not have been possible without the cooperation of those modelling groups who submitted simulations to PlioMIP (see table S1). It was financed in part by grants FAPESP2016/23670-0, FAPESP-2015/17659-0, CNPq-301726/2013-2; CNPq-405869/2013-4; CNPqMCT-INCT-59 CRIO-573720/2008-8, and Coordenação de Aperfeiçoamento de Pessoal de Nível Superior - Brasil (CAPES) Finance Code 001 (grant number 88882.151076/2017-01). 


\section{References}

Brierley C, Wainer I (2018) Inter-annual variability in the tropical Atlantic from the Last Glacial Maximum into future climate projections simulated by CMIP5/PMIP3. Clim Past 14:1377-1390. doi: 10.5194/cp-14-13772018

Brierley CM (2015) Interannual climate variability seen in the Pliocene Model Intercomparison Project. Clim Past 11:605-618. doi: 10.5194/cp-11-605-2015

Brierley CM, Fedorov a V, Liu Z, et al (2009) Greatly Expanded Tropical Warm Pool and Waekened Hadley Circulation in the Early Pliocene. Science (80- ) 323:1714-1718. doi: 10.1126/science.1167625

Cai W, Wu L, Lengaigne M, et al (2019) Pantropical climate interactions. Science 363:eaav4236. doi: 10.1126/science.aav4236

Chandan D, Peltier WR (2017) Regional and global climate for the mid-Pliocene using the University of Toronto version of CCSM4 and PlioMIP2 boundary conditions. Clim Past 13:919-942. doi: https://doi.org/10.5194/cp13-919-2017

De Schepper S, Head MJ, Groeneveld J (2009) North Atlantic Current variability through marine isotope stage M2 (circa 3.3 Ma) during the mid-Pliocene. Paleoceanography 24:. doi: 10.1029/2008PA001725

Delworth TL, Greatbatch RJ (2000) Multidecadal Thermohaline Circulation Variability Driven by Atmospheric Surface Flux Forcing

Delworth TL, Mann ME (2000) Observed and simulated multidecadal variability in the Northern Hemisphere. Clim Dyn 16:661-676. doi: 10.1007/s003820000075

Denton GH, Prentice ML, Kellogg DE, Kellogg TB (1984) Late Tertiary history of the Antarctic ice sheet : Evidence from the Dry Valleys. Geology 12:263-267

Deser C, Alexander MA, Xie S-P, Phillips AS (2010) Sea Surface Temperature Variability: Patterns and Mechanisms. Annu Rev Mar Sci 2:115-43. doi: 10.1146/annurev-marine-120408-151453

Dolan AM, Haywood AM, Hill DJ, et al (2011) Sensitivity of Pliocene ice sheets to orbital forcing. Palaeogeogr Palaeoclimatol Palaeoecol 309:98-110. doi: 10.1016/j.palaeo.2011.03.030

Dowsett H, Robinson M, Haywood AM, et al (2010) The PRISM3D paleoenvironmental reconstruction. Stratigraphy 7:123-139

Dowsett HJ, Chandler MA, Cronin TM, Dwyer GS (2005) Middle Pliocene sea surface temperature variability. Paleoceanography 20:1-8. doi: 10.1029/2005PA001133

Dowsett HJ, Robinson MM, Haywood AM, et al (2012) Assessing confidence in Pliocene sea surface temperatures to evaluate predictive models. Nat Clim Chang 2:365-371. doi: 10.1038/nclimate1455

Draut AE, Raymo ME, Mcmanus JF, Oppo DW (2003) Climate stability during the Pliocene warm period. Paleoceanography 18:1-12. doi: 10.1029/2003PA000889

Enfield DB, Mesta-Nuñes A, Trimble PJ (2001) The Atlantic multidecadal oscillation and its relation to rainfall and river flow in the continental US. Geophys Res Lett 28:2077-2080

Fedorov A V, Brierley CM, Emanuel K (2010) Tropical cyclones and permanent El Niño in the early Pliocene 
epoch. Nature 463:1066-1071. doi: 10.1038/nature08831

Friedrich O, Wilson PA, Bolton CT, et al (2013) Late Pliocene to early Pleistocene changes in the North Atlantic Current and suborbital-scale sea-surface temperature variability. Paleoceanography 28:274-282. doi: 10.1002/palo.20029

Giannini A, Saravanan R, Chang P (2003) Oceanic Forcing of Sahel Rainfall on Interannual to Interdecadal Time Scales. Science (80- ) 302:1027-1030. doi: 10.1126/science.1089357

Haywood AM, Dowsett HJ, Robinson MM, et al (2011) Pliocene Model Intercomparison Project ( PlioMIP ): experimental design and boundary conditions ( Experiment 2 ). Geosci Model Dev 4:571-577. doi: 10.5194/gmd-4-571-2011

Haywood AM, Valdes PJ, Peck VL (2007) A permanent El Ni??o-like state during the Pliocene? Paleoceanography 22:1-21. doi: 10.1029/2006PA001323

Lübbecke JF, Rodríguez-Fonseca B, Richter I, et al (2018) Equatorial Atlantic variability-Modes, mechanisms, and global teleconnections. Wiley Interdiscip Rev Clim Chang 9:e527. doi: 10.1002/wcc.527

Morioka Y, Tozuka T, Yamagata T, et al (2011) On the Growth and Decay of the Subtropical Dipole Mode in the South Atlantic. J Clim 24:5538-5554. doi: 10.1175/2011JCLI4010.1

Mudelsee M (2014) Spectral Analysis. pp 169-215

Pontes GM, Gupta A Sen, Taschetto AS (2016) Projected changes to South Atlantic boundary currents and confluence region in the CMIP5 models: the role of wind and deep ocean changes. Environ Res Lett 11:1-9. doi: 10.1088/1748-9326/11/9/094013

Power S, Delage F, Chung C, et al (2013) Robust twenty-first-century projections of El Niño and related precipitation variability. Nature 502:. doi: 10.1038/nature12580

Rehfeld K, Münch T, Ho SL, Laepple T (2018) Global patterns of declining temperature variability from the Last Glacial Maximum to the Holocene. Nature 554:356-359. doi: 10.1038/nature25454

Sarmiento JL, Bryan K (1982) An ocean transport model for the North Atlantic. J Geophys Res 87:394. doi: 10.1029/JC087iC01p00394

Scroxton N, Bonham SG, Rickaby REM, et al (2011) Persistent El Niño-Southern Oscillation variation during the Pliocene Epoch. Paleoceanography 26:1-13. doi: 10.1029/2010PA002097

Seki O, Foster GL, Schmidt DN, et al (2010) Alkenone and boron-based Pliocene pCO2 records. Earth Planet Sci Lett 292:201-211. doi: 10.1016/j.epsl.2010.01.037

Taschetto AS, Sen Gupta A, Jourdain NC, et al (2014) Cold Tongue and Warm Pool ENSO Events in CMIP5: Mean State and Future Projections. J Clim 27:2861-2885. doi: 10.1175/JCLI-D-13-00437.1

Tindall JC, Haywood AM, Howell FW (2016) Accounting for centennial-scale variability when detecting changes in ENSO: A study of the Pliocene. Paleoceanography 31:1330-1349. doi: 10.1002/2016PA002951

Ting M, Kushnir Y, Seager R, Li C (2011) Robust features of Atlantic multi-decadal variability and its climate impacts. Geophys Res Lett 38:1-6. doi: 10.1029/2011GL048712

Trenberth KE, Shea DJ (2006) Atlantic hurricanes and natural variability in 2005. Geophys Res Lett 33:1-4. doi: 10.1029/2006GL026894 
Tzedakis PC, Drysdale RN, Margari V, et al (2018) Enhanced climate instability in the North Atlantic and southern Europe during the Last Interglacial. Nat Commun 9:1-14. doi: 10.1038/s41467-018-06683-3

Wainer I, Prado LF, Khodri M, Otto-Bliesner B (2014) Reconstruction of the South Atlantic Subtropical Dipole index for the past 12,000 years from surface temperature proxy. Sci Rep 4:1-8. doi: 10.1038/srep05291

Wainer I, Soares J (1997) North northeast Brazil rainfall and its decadal-scale relationship to wind stress and sea surface temperature. Geophys Res Lett 24:277-280. doi: 10.1029/96GL03970

Watanabe T, Suzuki A, Minobe S, et al (2011) Permanent El Niño during the Pliocene warm period not supported by coral evidence. Nature 471:209-211. doi: 10.1038/nature09777

Zebiak SE (1993) Air-Sea Interaction in the Equatorial Atlantic Region. J. Clim. 6:1567-1586 